Published in final edited form as:

J Viral Hepat. 2015 November ; 22(11): 936-947. doi:10.1111/jvh.12398.

\title{
Increased Risk of Hip Fracture Associated with Dually-Treated HIV/Hepatitis B Virus Coinfection
}

\author{
Dana D. Byrne ${ }^{1,2,3}$, Craig W. Newcomb², Dena M. Carbonari ${ }^{2,3}$, Melissa S. Nezamzadeh ${ }^{2,3}$, \\ Kimberly B. F. Leidl ${ }^{2}$, Maximilian Herlim², Yu-Xiao Yang ${ }^{1,2,3}$, Sean Hennessy ${ }^{2,3}$, Jay R. \\ Kostman $^{1,4}$, Mary B. Leonard ${ }^{2,4,5}$, A. Russell Localio ${ }^{2}$, and Vincent Lo Re ${ }^{1,2,3,4}$ [III] \\ ${ }^{1}$ Department of Medicine, Perelman School of Medicine, University of Pennsylvania, Philadelphia, \\ PA
}

${ }^{2}$ Department of Biostatistics and Epidemiology, Center for Clinical Epidemiology and Biostatistics, Perelman School of Medicine, University of Pennsylvania, Philadelphia, PA

${ }^{3}$ Center for Pharmacoepidemiology Research and Training, Perelman School of Medicine, University of Pennsylvania, Philadelphia, PA

${ }^{4}$ Penn Center for AIDS Research, University of Pennsylvania, Philadelphia, PA, USA

${ }^{5}$ Department of Pediatrics, The Children's Hospital of Philadelphia, Perelman School of Medicine, University of Pennsylvania, Philadelphia, PA

\section{Abstract}

HIV and hepatitis B virus (HBV) infection are each associated with reduced bone mineral density, but it is unclear whether HIV/HBV coinfection is associated with an increased risk of fracture. We determined whether dually-treated HIV/HBV patients have a higher incidence of hip fracture compared to treated HBV-monoinfected, antiretroviral therapy (ART)-treated HIV-monoinfected, and HIV/HBV-uninfected patients. We conducted a cohort study among 4,156 dually-treated HIV/ HBV-coinfected, 2,053 treated HBV-monoinfected, 96,253 ART-treated HIV-monoinfected, and 746,794 randomly sampled uninfected persons within the U.S. Medicaid populations of California, Florida, New York, Ohio, and Pennsylvania (1999-2007). Coinfected patients were matched on propensity score to persons in each comparator cohort. Weighted survival models accounting for competing risks were used to estimate cumulative incidences and hazard ratios (HRs) with 95\% confidence intervals (CIs) of incident hip fracture for dually-treated coinfected patients compared to: 1) HBV-monoinfected receiving nucleos(t)ide analogue or interferon alfa therapy, 2) HIV-

Address Correspondence to: Vincent Lo Re III, MD, MSCE Center for Clinical Epidemiology and Biostatistics University of Pennsylvania School of Medicine 836 Blockley Hall, 423 Guardian Drive Philadelphia, PA 19104-6021 vincentl@mail.med.upenn.edu Tel: 215-573-5964 Fax: 215-573-5315.

Conflicts of Interest: Dr. Vincent Lo Re III has received research grant support (to the University of Pennsylvania) from AstraZeneca, Gilead Sciences, and Merck. Dr. Sean Hennessy has been supported by research funding provided to Penn from AstraZeneca, BristolMyers Squibb, and Gilead Sciences, Inc. and has served as a consultant to AstraZeneca and Bristol-Myers Squibb. Dr. Jay R. Kostman has served as a consultant to Merck and Vertex. All other authors report no disclosures.

DISCLOSURES

V.L.R. has been supported by research funding provided to Penn from AstraZeneca and Gilead Sciences. S.H. has been supported by research funding provided to Penn from AstraZeneca, Bristol-Myers Squibb, and Gilead Sciences, Inc. and has served as a consultant to AstraZeneca and Bristol-Myers Squibb. J.R.K. has served as a consultant to Merck and Vertex. All other authors report no disclosures. 
monoinfected on ART, and 3) uninfected persons. Dually-treated coinfected patients had a higher cumulative incidence of hip fracture compared to ART-treated HIV-monoinfected (at 5 years: $1.70 \%$ versus $1.24 \%$; adjusted HR, 1.37 [95\% CI, 1.03-1.83]) and uninfected (at 5 years: $1.64 \%$ versus 1.22\%; adjusted HR, 1.35 [95\% CI, 1.03-1.84]) persons. The cumulative incidence of hip fracture was higher among coinfected than treated HBV-monoinfected patients (at 5 years: $0.70 \%$ versus $0.27 \%$ ), but this difference was not statistically significant in competing risk analysis (adjusted HR, 2.62 [95\% CI, 0.92-7.51]). Among Medicaid enrollees, the risk of hip fracture was higher among dually-treated HIV/HBV-coinfected patients than ART-treated HIV-monoinfected and uninfected persons.

\section{Keywords}

fracture; HIV; hepatitis B; HIV/hepatitis B; bone

\section{INTRODUCTION}

In addition to its effects on the liver, chronic hepatitis B virus (HBV) infection can affect organ systems outside of the gastrointestinal tract, particularly the skeletal system [1-3]. Cross-sectional studies in chronic HBV-infected patients alone $[4,5]$ and among noncirrhotic chronic HBV- and hepatitis $\mathrm{C}$ virus-infected patients [6-9] have shown that HBVinfected patients have reduced bone mineral density (BMD) compared to uninfected persons. Further, a recent cohort study demonstrated that untreated chronic HBV-infected patients have higher rates of hip fracture compared to uninfected persons, and rates remained higher when patients with hepatic decompensation were excluded from comparisons [10]. Chronic HBV-infected patients with decompensated cirrhosis had higher rates of hip fracture than HBV-infected patients without diagnoses of hepatic decompensation. A number of factors related to chronic HBV infection have been hypothesized to contribute to low BMD and increased risk of fracture. Chronic HBVassociated inflammation could inhibit bone formation and increase bone resorption, leading to a decrease in BMD [11]. The development of HBV-related hepatic decompensation could further contribute to a decrease in BMD by impairing production of factors (e.g., 25hydroxyvitamin D, insulin-like growth factor-1) that promote bone formation [2, 3].

Low BMD is also a recognized metabolic complication of HIV infection [12-15]. One metaanalysis showed that the prevalence of osteoporosis was three times higher among HIVinfected than uninfected patients [16]. Further, BMD decreases within the first two years of antiretroviral therapy (ART) initiation [16-20], though becomes stable with established ART [21-23]. Subsequent longitudinal studies have shown that HIV-infected patients have increased fracture rates compared to uninfected persons [24, 25]. HIV-related chronic inflammation, ART-related factors, increased prevalence of tobacco/alcohol use and low vitamin D levels, and traditional osteoporosis risk factors exacerbated by HIV (e.g., poor nutrition, low body weight) all likely contribute to the low BMD and increased fracture risk in HIV [13, 17, 20, 21]. 
Few studies have examined the risk of fracture associated with HIV/HBV coinfection. Quantifying this risk is important since HBV coinfection is present in 6-14\% of HIVinfected persons in North America [26] and because fractures, particularly those of the hip, adversely affect survival, with an effect on mortality similar to that of cardiovascular disease [27]. We evaluated data from U.S. Medicaid, a joint federal and state program that provides funding for medical care and prescription drug benefits for low-income and special-needs individuals [28], to measure the risk of hip fracture among dually-treated HIV/HBVcoinfected patients compared to those with treated chronic HBV monoinfection, ARTtreated HIV monoinfection, and persons uninfected with either virus. Our rationale for performing these three comparisons was to allow a more complete understanding of the hip fracture risk associated with HIV/HBV coinfection. We hypothesized that dual infection increases the hip fracture incidence compared to HBV-monoinfected, HIV-monoinfected, and uninfected individuals.

\section{PATIENTS AND METHODS}

\section{Study Design and Data Source}

We performed a retrospective cohort study among HIV/HBV-coinfected, HBVmonoinfected, HIV-monoinfected, and HIV/HBV-uninfected persons within the U.S. using Medicaid data from California, Florida, New York, Ohio, and Pennsylvania between January 1, 1999 and December 31, 2007. The states included in this study represent five of the largest Medicaid programs in the U.S., accounting for approximately 35\% of Medicaid enrollees nationwide [29, 30]. Medicaid data report demographic information, inpatient and outpatient diagnoses (recorded using International Classification of Diseases, Ninth Revision [ICD-9] codes), and dispensed medications. Laboratory tests that were performed can be identified, but results are not recorded in the Medicaid database. Death dates were determined using Medicaid and Social Security Administration Death Master File data. Since $17 \%$ of Medicaid beneficiaries are co-enrolled in the U.S. Medicare program, we obtained Medicare data on dually-eligible persons to ensure no diagnoses were missed [31]. The study was approved by the University of Pennsylvania Institutional Review Board, and a data use agreement was obtained from the Centers for Medicare and Medicaid Services.

\section{Study Patients}

We used previously validated ICD-9 diagnoses to identify patients with chronic HBV and HIV infections (Supplementary Table 1) [32, 33]. Exposure status was determined by evaluating all claims recorded for each Medicaid patient between 1999 and 2007. As a result, patients only contributed follow-up time to one cohort. Since current guidelines recommend ART in all HIV/HBV patients regardless of CD4 count [34], only dually-treated coinfected patients were included in the coinfected cohort. Although the early years of the Medicaid data analyzed included observation time during which HIV treatment guidelines did not recommend that anti-HBV-active ART be administered to all HIV/HBV patients, we sought results that would be generalizable to patients treated under current HIV/HBV treatment guidelines and so included only HIV/HBV patients who received dual HIV/HBV therapy. To ensure appropriate comparability, only treated chronic HBV-and ART-treated HIV-monoinfected patients were selected as comparator cohorts. 
Patients aged 18 years or older with at least 180 days of Medicaid enrollment were eligible for inclusion. Dually-treated coinfected patients had: 1) diagnosis of chronic HBV infection, 2) diagnosis of HIV infection, 3) prescription claims indicative of ART (defined as use of at least three antiretrovirals from two different classes [34] or 23 nucleoside analogues, a previously accepted ART regimen [35]), and 4) prescription claims for an anti-HBV-active antiretroviral (i.e., emtricitabine, lamivudine, and/or tenofovir) and/or an antiviral used to treat chronic HBV (i.e., adefovir, entecavir, telbivudine, and/or interferon alfa). Treated HBV-monoinfected patients had: 1) chronic HBV diagnosis, 2) prescription claims for antiHBV therapy (i.e., adefovir, emtricitabine, entecavir, lamivudine, telbivudine, tenofovir, and/or interferon alfa), and 3) neither diagnosis of HIV infection nor prescriptions for antiretroviral drugs other than lamivudine, emtricitabine, or tenofovir. ART-treated HIVmonoinfected patients had: 1) diagnosis of HIV, 2) prescription claims indicative of ART, and 3) no chronic HBV diagnosis or prescriptions for non-antiretroviral antivirals used to treat chronic HBV (i.e., adefovir, entecavir, telbivudine, and/or interferon alfa). HIV/HBVuninfected patients had no HBV or HIV diagnoses and no claims for antiretrovirals or antivirals used to treat chronic HBV.

Patients were excluded if they had: 1) no claims after becoming eligible for the study (i.e., no follow-up), 2) hip fracture diagnosis prior to start of follow-up (defined below), 3) diagnosis of hepatitis $\mathrm{C}$ virus infection (to isolate the effect of dually-treated HIV/HBV coinfection and since chronic hepatitis $\mathrm{C}$ is associated with an increased risk of hip fracture [36]), 4) acute HBV diagnosis only, or 5) Asian/Pacific Islander race (since fracture rates differ significantly by race/ethnicity [37-40] and because the HIV/HBV-coinfected cohort included very few Asians/Pacific Islanders). ICD-9 diagnoses for hepatitis $\mathrm{C}$ and acute HBV are listed in Supplementary Table 1.

All eligible coinfected, HBV-monoinfected, and HIV-monoinfected patients were included. We selected a 5\% systematic random sample of uninfected patients stratified on age, sex, and state, to reduce to workable proportions the number of uninfected individuals for further matching and analysis and to ensure the representativeness of this sample to the uninfected population [41]. Systematic random selection facilitated the acquisition of balanced samples across age, sex, and state.

Follow-up for uninfected patients began 180 days after their first Medicaid claim. Follow-up for dually-treated coinfected, treated HBV-monoinfected, and antiretroviral-treated HIVmonoinfected patients began on the date their respective drug therapies were dispensed. Within each cohort, the six months prior to the start of follow-up represented the baseline period, during which baseline comorbidities and therapies were identified. If a coinfected, HBV-monoinfected, or HIV-monoinfected patient did not have at least six months of observation in Medicaid at the time their antiviral therapy was initially dispensed, follow-up began after 180 days of enrollment in the Medicaid program. Within each cohort, follow-up continued until diagnosis of hip fracture, death, or last claim before December 31, 2007.

\section{Main Outcome}

The primary outcome was incident fracture of the proximal femur (hip). Hip fracture diagnoses (Supplementary Table 1) in Medicaid were found to be highly valid in a 
previous survey, with $94 \%$ of coded diagnoses confirmed via medical records [42]. We focused on hip fractures as our main endpoint because such events are unlikely to be susceptible to surveillance bias.

\section{Data Collection}

Demographic data included: age, sex, race/ethnicity, and state. Baseline comorbidities and medications associated with osteoporosis or risk of falls were also collected (Table 1). Patients were considered exposed to a drug if a prescription claim was recorded during the baseline period.

\section{Statistical Analysis}

The primary analysis compared the time to incident hip fracture in: 1) dually-treated coinfected versus treated HBV-monoinfected (to examine the effect of treated HIV on hip fracture risk in the setting of treated chronic HBV), 2) dually-treated coinfected versus ART-treated HIV-monoinfected (to examine the effect of treated chronic HBV on hip fracture risk in the setting of treated HIV), and 3) dually-treated coinfected versus uninfected persons (to examine the effects of dually-treated HIV/HBV on hip fracture risk). These three comparisons were evaluated in order to fully disentangle the effects of the underlying diseases and treatments on hip fracture rates. We first estimated unadjusted incidence rates (in events/1,000 person-years) of hip fracture for each cohort.

Differences in baseline comorbidities and usage of medications associated with osteoporosis were observed among the three cohorts (Table 1). Because of the large number of potential confounding variables relative to the number of hip fractures, we used logistic regression with treatment/exposure status as the outcome to estimate propensity scores as a method to control for these variables [43, 44]. Each comparison of interest used a tailored propensity score model. All variables in Table 1 were included in propensity score models except for follow-up time. We also excluded age and sex (to allow us to evaluate these variables as effect modifiers) and hepatic decompensation (since this might be in the causal pathway to fracture) from propensity score models.

We then matched on propensity scores persons within each of the three comparator cohorts to coinfected patients. This matching enabled us to create comparison groups of HBVmonoinfected, HIV-monoinfected, and uninfected persons that had baseline characteristics that resembled those of the coinfected cohort. For the comparison of the coinfected cohort with the HBV-monoinfected cohort, we used 1:1 matching for the subset of coinfected patients that had suitable matches. For the comparisons of the coinfected cohort with the HIV-monoinfected and uninfected cohorts, we were able to match up to four persons from each of these cohorts to coinfected patients. All matching used nearest-neighbor methods and a caliper of one-fourth of the standard deviation of the propensity score on the log odds scale [45].

Because of the variable number of matches for each coinfected patient with persons within the HIV-monoinfected and uninfected cohorts, we used a weighted analysis, with weights of coinfected patients equaling 1.0 and weights of patients within the two comparator cohorts 
equaling the inverse of the number of comparator patients in the matched set. This form of weighting ensured that the weighted sum of each matched patient in each comparator cohort would equal the sample size of the coinfected cohort. It also ensured that patients in the comparator cohorts were similar in characteristics included in the propensity score to the coinfected patients [45]. Balance in characteristics between the cohorts after matching is demonstrated in Supplementary Table 2. Since age and sex were not included in propensity scores (to permit their evaluation as effect modifiers), these variables were not balanced across the cohorts.

Weighted survival models accounting for the competing risk of death were then used to estimate cumulative incidences (i.e., risks) and hazard ratios (HRs) of hip fracture [46]. Robust (empirical) variance estimates and their 95\% confidence intervals (CIs) compensated for the effects of weights [47]. The final models included main effects for HIV/HBV status, age, and sex and were standardized to the coinfected sample based on age and sex. Details appear in the Supplementary Appendix. Because the anti-HBV-active antiretroviral medication tenofovir is recommended as HBV treatment (along with either emtricitabine or lamivudine) in HIV/HBV-coinfected patients [34] and has been shown to be associated with declines in BMD [17, 18, 20] and a potentially higher risk of osteoporotic fractures [48], analyses of hip fracture events between dually-treated coinfected and ART-treated HIVmonoinfected patients were additionally adjusted for baseline tenofovir use after propensity score-based matching. This additional adjustment produced a slightly different cumulative incidence of hip fracture for the coinfected cohort. Further, since we were only able to match a small subset of coinfected patients to HBV-monoinfected patients, the cumulative incidence of hip fracture for the coinfected cohort in this comparison also differed from that of the other comparisons. Data were analyzed using SAS 9.3 (SAS Institute Inc., Cary, NC) for sampling and matching, and Stata 13.1 (Stata Corporation., College Station, TX) for the weighted regression analyses.

\section{RESULTS}

Among 42,287,481 persons enrolled in U.S. Medicaid among the five states between 1999 and 2007 (Figure 1), we identified 4,156 dually-treated coinfected, 2,053 treated HBVmonoinfected, and 96,253 ART-treated HIV-monoinfected patients who met inclusion criteria. Among the uninfected persons who met inclusion criteria, 746,794 were randomly selected for inclusion.

Table 1 summarizes the demographic and clinical characteristics of the cohorts. HBVmonoinfected patients were older, more frequently female, and more commonly of white race than coinfected and HIV-monoinfected patients. HBV-monoinfected patients also more frequently had diagnoses of cancer and hepatic decompensation and more commonly received calcium and vitamin D supplements, bisphosphonates, and proton pump inhibitors. Coinfected patients more commonly had diagnoses of alcoholism, dementia, seizure disorder, depression, and asthma than either HBV- or HIV-monoinfected individuals. Baseline tenofovir use was more common among coinfected (21.6\%) than HIVmonoinfected (17.6\%) persons. The mean follow-up time ranged from 2.2 years for HBVmonoinfected patients to 4.6 years for coinfected patients (Table 1). A higher proportion of 
coinfected persons died during follow-up (649 [15.6\%]) compared to HBV-monoinfected (157 [7.6\%]), HIV-monoinfected (12,056 [12.5\%]), and uninfected (51,079 [6.8\%]) persons.

The unadjusted incidence rate of hip fracture was 3.5 (95\% CI, $2.7-4.4)$ events/1,000 person-years for coinfected, 2.5 (95\% CI, 1.2 - 4.4) events/1,000 person-years for HBVmonoinfected, 2.1 (95\% CI, 2.0 - 2.3) events/1,000 person-years for HIV-monoinfected, and 4.5 (95\% CI, 4.4 - 4.6) events/1,000 person-years for uninfected persons (Table 2).

After the initial propensity-score-based matching (Supplementary Table 2) and then after further standardizing to the age and sex of the coinfected cohort, dually-treated coinfected patients had a higher cumulative incidence of hip fracture at five years compared to treated HBV-monoinfected persons $(0.70 \%$ versus $0.27 \%)$, but this difference was not statistically significant in competing risk analysis (adjusted HR, 2.62 [95\% CI, 0.92-7.51]; Figure 2a). However, coinfected patients had a significantly higher cumulative incidence of hip fracture compared to HIV-monoinfected (at 5 years: $1.70 \%$ versus $1.24 \%$; adjusted HR, 1.37 [95\% CI, 1.03-1.83]); Figure 2b) and HIV/HBV-uninfected (at 5 years: $1.64 \%$ versus $1.22 \%$; adjusted HR, 1.35 [95\% CI, 1.03-1.84]; Figure 2c) persons. At five years, dually-treated HIV/HBV coinfection was associated with 4.3 and 4.6 additional hip fractures per 1,000 compared to treated HBV-monoinfected and ART-treated HIV-monoinfected persons, respectively, and 4.2 additional hip fractures per 1,000 compared to uninfected persons (Table 2).

\section{DISCUSSION}

This study of U.S. Medicaid enrollees found that despite anti-HBV-active ART, HIV/HBVcoinfected patients had a higher risk of hip fracture compared to ART-treated HIVmonoinfected and HIV/HBV-uninfected persons. The cumulative incidence of hip fracture was higher among coinfected than treated HBV-monoinfected patients, but this difference was not statistically significant in competing risk analysis. This is the first study identifying an increased risk of hip fracture associated with HIV/HBV coinfection. These findings provide evidence that $\mathrm{HIV/HBV}$ coinfection is associated with adverse clinical bone outcomes despite anti-HBV-active ART.

The mechanisms for increased risk of hip fracture associated with HIV/HBV coinfection remain unknown. Inflammatory cytokines associated with both HIV and chronic HBV infections, particularly tumor necrosis factor-alpha, interleukin-1, and interleukin-6, can increase receptor activator of nuclear factor kappa-B ligand (RANKL), which stimulates osteoclastogenesis and bone resorption [11, 49, 50]. Tumor necrosis factor-alpha also promotes osteoblast apoptosis and inhibits osteoblast differentiation [50, 51]. Progressive $\mathrm{HBV}$-associated liver dysfunction can also increase the risk of hypogonadism [52], reduce hepatic hydroxylation of vitamin D [1], and impair hepatic production of insulin-like growth factor-1, which promotes bone formation [3]. HIV infection is associated with other osteoporosis risk factors, such as hypogonadism, lipoatrophy, decreased muscle mass, and low body mass index [19-21]. Moreover, initiation of ART is associated with significant short-term bone loss in the range of 2-6\% over 1-2 years [16-20]. Finally, traditional osteoporosis risk factors, such as alcohol abuse, tobacco dependence, poor nutrition, and 
fragility, might be more prevalent among coinfected patients and contribute to increased fracture risk from trauma, irrespective of the impact of chronic HBV on BMD. The mechanisms by which dually-treated HIV/HBV affects BMD and fracture risk require further study.

We observed that the risk of hip fracture at five years was higher among dually-treated coinfected patients compared to treated HBV-monoinfected patients $(0.70 \%$ versus $0.27 \%$; adjusted HR, 2.62 [95\% CI, 0.92-7.51]), but this difference was not statistically significant. The relatively small sample of treated HBV-monoinfected patients in our analysis likely contributed to our inability to detect a statistically significant difference in hip fracture risk between the coinfected and HBV-monoinfected cohorts. Alternatively, if the treated HBVmonoinfected patients in this study less commonly achieved HBV DNA suppression compared to the dually-treated coinfected patients, this could have led to higher levels of chronic HBV-associated inflammatory cytokines in the HBV-monoinfected cohort, which could have resulted in our finding a similar hip fracture risk compared to the coinfected cohort. Since the Medicaid database does not collect laboratory results, we cannot confirm this hypothesis.

Although a higher risk of fracture associated with dually-treated HIV/HBV coinfection has potential implications for clinical management, specific recommendations have not been made for BMD screening in the setting of either chronic HBV or HIV/HBV coinfection. It has been recommended that HIV-infected patients with fragility fractures, HIV-infected post-menopausal women, and all HIV-infected men 250 years of age undergo BMD screening. Additional studies are needed to determine the relation between dual-energy xray absorptiometry estimates of BMD and fracture risks associated with HIV/HBV coinfection, and to develop guidelines for the identification of patients at risk. Determination of the mechanisms of reduced BMD due to HIV/HBV coinfection is also needed to identify potential interventions that might prevent bone loss and mitigate fracture risk in this population.

Our study had several limitations. First, we lacked laboratory data to confirm chronic HBV infection and did not have radiographic determination of fracture diagnoses. We also could not assess whether fractures were specifically trauma-related. However, diagnoses of chronic HBV infection [32] and hip fracture [42] were identified using previously validated definitions. HIV/HBV-coinfected, HBV-monoinfected, and HIV-infected patients were only included if they had prescription claims for antiretroviral and/or anti-HBV therapies, reducing the likelihood of exposure misclassification. There is the potential that ARTtreated HIV-monoinfected patients receiving tenofovir, emtricitabine, or lamivudine might have had chronic HBV infection but not had a diagnosis recorded. However, such misclassification would have biased the results of our analysis comparing coinfected to HIV-monoinfected patients towards a null association.

Second, we observed major differences between the cohorts in the prevalence of comorbidities and drugs associated with osteoporosis. However, we used propensity score matching to balance potential confounders across comparison groups. 
Third, residual confounding by unmeasured factors is possible. We did not have information on body mass index, smoking, illicit drug use, and duration of HIV and HBV infections. In addition, the absence of laboratory data on hepatitis B e antigen and antibody status, hepatitis B DNA, and extent of hepatic fibrosis did not allow us to determine the stage of chronic HBV infection for patients in this analysis. Further, we did not have HIV RNA or HBV DNA data to permit subanalyses among coinfected patients with fully suppressed HIV or HBV infections. Our analyses also only accounted for baseline use of tenofovir and pharmacologic therapies for osteoporosis.

Fourth, since our data covered an earlier period in the ART era (1999 - 2007), some HIV/HBV patients were treated with lamivudine alone and not with tenofovir plus either emtricitabine or lamivudine, which is the preferred regimen for these patients [34, 53]. Since tenofovir is a more potent anti-HBV agent than lamivudine [54], tenofovir-based anti-HBV therapy more commonly leads to HBV DNA suppression, which could potentially mitigate the hepatic and systemic inflammation induced by chronic HBV that is hypothesized to be an important contributor to the increased fracture risk among these patients.

Finally, the study population consisted of U.S. Medicaid enrollees and might not be generalizable to other settings. However, Medicaid is a large source of care for patients with HIV infection in the U.S. and provides coverage to a large proportion of patients with chronic HBV [55]. The study cohorts are demographically similar to U.S. HIV and HIV/HBV populations [56, 57]. In addition, in spite of the large number of patients in the study, we were not able to match all coinfected patients successfully. For that reason, and in the interests of arriving at unbiased estimates between coinfected patients and HBV monoinfected patients, we had to limit this comparison to a subset of coinfected patients. This restriction might limit the generalizability of one of our findings (Figure 2a).

In conclusion, we found that the risk of hip fracture was increased among dually-treated HIV/HBV-coinfected patients compared to ART-treated HIV-monoinfected and uninfected persons. Future studies should examine mechanisms for bone disease as well as interventions and therapies to prevent fractures among coinfected patients.

\section{Supplementary Material}

Refer to Web version on PubMed Central for supplementary material.

\section{ACKNOWLEDGEMENTS}

This study was supported by an investigator-initiated research grant (to the University of Pennsylvania) from Gilead Sciences, Inc. Dr. Hennessy receives further support from grant R01AG025152 from the National Institutes of Health.

These results were presented, in part, at ID Week 2014, October 8-12, 2014, Philadelphia, PA, USA [Abstract 1603 ] and the $30^{\text {th }}$ International Conference on Pharmacoepidemiology \& Therapeutic Risk Management, October 24-27, 2014, Taipei, Taiwan [Oral Abstract 25].

Sources of Funding: This study was supported by an investigator-initiated research grant (to the University of Pennsylvania) from Gilead Sciences, Inc. Dr. Hennessy receives further support from grant R01AG025152 from the National Institutes of Health. 


\section{List of Abbreviations in the order of appearance}

$\begin{array}{ll}\text { HIV } & \text { Human immunodeficiency virus } \\ \text { HBV } & \text { Hepatitis B virus } \\ \text { ART } & \text { Antiretroviral therapy } \\ \text { HR } & \text { Hazard ratio } \\ \text { CI } & \text { Confidence interval } \\ \text { BMD } & \text { Bone mineral density } \\ \text { ICD-9-CM } & \text { International Classification of Diseases, Ninth Revision, Clinical } \\ & \text { Modification }\end{array}$

RANKL receptor activator of nuclear factor kappa-B ligand

\section{REFERENCES}

1. Hay JE. Bone disease in cholestatic liver disease. Gastroenterology. 1995; 108:276-283. [PubMed: 7806050]

2. Leslie WD, Bernstein CN, Leboff MS. AGA technical review on osteoporosis in hepatic disorders. Gastroenterology. 2003; 125:941-966. [PubMed: 12949738]

3. Rouillard S, Lane NE. Hepatic osteodystrophy. Hepatology. 2001; 33:301-307. [PubMed: 11124849]

4. Fung, S.; Fabri, M.; Wong, F.; Heathcote, J.; Gurel, S.; Kwan, WCP., et al. Reduced bone mineral density derived from dual x-ray absorptiometry (DEXA) assessments in patients with chronic hepatitis B (CHB).. 46th Annual Meeting of the European Association for the Study of the Liver; Berlin, Germany. March 30 - April 3, 2011; [Abstract 2382]

5. Gill US, Zissimopoulos A, Al-Shamma S, Burke K, McPhail MJ, Barr DA, et al. Assessment of bone mineral density in tenofovir-treated patients with chronic hepatitis B: Can the fracture risk assessment tool identify those at greatest risk? J Infect Dis. 2014

6. Olsson R, Johansson C, Lindstedt G, Mellstrom D. Risk factors for bone loss in chronic active hepatitis and primary biliary cirrhosis. Scand J Gastroenterol. 1994; 29:753-756. [PubMed: 7973437]

7. Schiefke I, Fach A, Wiedmann M, Aretin AV, Schenker E, Borte G, et al. Reduced bone mineral density and altered bone turnover markers in patients with non-cirrhotic chronic hepatitis $\mathrm{B}$ or $\mathrm{C}$ infection. World J Gastroenterol. 2005; 11:1843-1847. [PubMed: 15793878]

8. Lo Re V 3rd, Guaraldi G, Leonard MB, Localio AR, Lin J, Orlando G, et al. Viral hepatitis is associated with reduced bone mineral density in HIV-infected women but not men. AIDS. 2009; 23:2191-2198. [PubMed: 19779322]

9. Lawson-Ayayi S, Cazanave C, Kpozehouen A, Barthe N, Mehsen N, Hessamfar M, et al. Chronic viral hepatitis is associated with low bone mineral density in HIV-infected patients, ANRS CO 3 Aquitaine Cohort. J Acquir Immune Defic Syndr. 2013; 62:430-435. [PubMed: 23296138]

10. Byrne DD, Newcomb CW, Carbonari DM, Nezamzadeh MS, Leidl KB, Herlim M, et al. Risk of hip fracture associated with untreated and treated chronic hepatitis B virus infection. J Hepatol. 2014; 61:210-218. [PubMed: 24713185]

11. Gonzalez-Calvin JL, Gallego-Rojo F, Fernandez-Perez R, Casado-Caballero F, Ruiz-Escolano E, Olivares EG. Osteoporosis, mineral metabolism, and serum soluble tumor necrosis factor receptor p55 in viral cirrhosis. J Clin Endocrinol Metab. 2004; 89:4325-4330. [PubMed: 15356028]

12. Grijsen ML, Vrouenraets SM, Steingrover R, Lips P, Reiss P, Wit FW, et al. High prevalence of reduced bone mineral density in primary HIV-1-infected men. AIDS. 2010; 24:2233-2238.

[PubMed: 20616695] 
13. McComsey GA, Tebas P, Shane E, Yin MT, Overton ET, Huang JS, et al. Bone disease in HIV infection: a practical review and recommendations for HIV care providers. Clin Infect Dis. 2010; 51:937-946. [PubMed: 20839968]

14. Mary-Krause M, Viard JP, Ename-Mkoumazok B, Bentata M, Valantin MA, Missy P, et al. Prevalence of low bone mineral density in men and women infected with human immunodeficiency virus 1 and a proposal for screening strategy. J Clin Densitom. 2012; 15:422433. [PubMed: 22819139]

15. Brown TT, Chen Y, Currier JS, Ribaudo HJ, Rothenberg J, Dube MP, et al. Body composition, soluble markers of inflammation, and bone mineral density in antiretroviral therapy-naive HIV-1infected individuals. J Acquir Immune Defic Syndr. 2013; 63:323-330. [PubMed: 23591634]

16. Brown TT, Qaqish RB. Antiretroviral therapy and the prevalence of osteopenia and osteoporosis: a meta-analytic review. AIDS. 2006; 20:2165-2174. [PubMed: 17086056]

17. Gallant JE, Staszewski S, Pozniak AL, DeJesus E, Suleiman JM, Miller MD, et al. Efficacy and safety of tenofovir DF vs stavudine in combination therapy in antiretroviral-naive patients: a 3year randomized trial. JAMA. 2004; 292:191-201. [PubMed: 15249568]

18. Cassetti I, Madruga JV, Suleiman JM, Etzel A, Zhong L, Cheng AK, et al. The safety and efficacy of tenofovir DF in combination with lamivudine and efavirenz through 6 years in antiretroviralnaive HIV-1-infected patients. HIV Clin Trials. 2007; 8:164-172. [PubMed: 17621463]

19. Duvivier C, Kolta S, Assoumou L, Ghosn J, Rozenberg S, Murphy RL, et al. Greater decrease in bone mineral density with protease inhibitor regimens compared with nonnucleoside reverse transcriptase inhibitor regimens in HIV-1 infected naive patients. AIDS. 2009; 23:817-824. [PubMed: 19363330]

20. McComsey GA, Kitch D, Daar ES, Tierney C, Jahed NC, Tebas P, et al. Bone mineral density and fractures in antiretroviral-naive persons randomized to receive abacavirlamivudine or tenofovir disoproxil fumarate-emtricitabine along with efavirenz or atazanavir-ritonavir: AIDS Clinical Trials Group A5224s, a substudy of ACTG A5202. J Infect Dis. 2011; 203:1791-1801. [PubMed: 21606537]

21. Mondy K, Yarasheski K, Powderly WG, Whyte M, Claxton S, DeMarco D, et al. Longitudinal evolution of bone mineral density and bone markers in human immunodeficiency virus-infected individuals. Clin Infect Dis. 2003; 36:482-490. [PubMed: 12567307]

22. Dolan SE, Kanter JR, Grinspoon S. Longitudinal analysis of bone density in human immunodeficiency virus-infected women. J Clin Endocrinol Metab. 2006; 91:2938-2945. [PubMed: 16735489]

23. Bolland MJ, Grey AB, Horne AM, Briggs SE, Thomas MG, Ellis-Pegler RB, et al. Bone mineral density is not reduced in HIV-infected Caucasian men treated with highly active antiretroviral therapy. Clin Endocrinol (Oxf). 2006; 65:191-197. [PubMed: 16886959]

24. Womack JA, Goulet JL, Gibert C, Brandt C, Chang CC, Gulanski B, et al. Increased risk of fragility fractures among HIV infected compared to uninfected male veterans. PLoS One. 2011; 6:e17217. [PubMed: 21359191]

25. Young B, Dao CN, Buchacz K, Baker R, Brooks JT. Increased rates of bone fracture among HIVinfected persons in the HIV Outpatient Study (HOPS) compared with the US general population, 2000-2006. Clin Infect Dis. 2011; 52:1061-1068. [PubMed: 21398272]

26. Kellerman SE, Hanson DL, McNaghten AD, Fleming PL. Prevalence of chronic hepatitis B and incidence of acute hepatitis B infection in human immunodeficiency virus-infected subjects. J Infect Dis. 2003; 188:571-577. [PubMed: 12898445]

27. Mittalhenkle A, Gillen DL, Stehman-Breen CO. Increased risk of mortality associated with hip fracture in the dialysis population. Am J Kidney Dis. 2004; 44:672-679. [PubMed: 15384018]

28. Hennessy S, Bilker WB, Weber A, Strom BL. Descriptive analyses of the integrity of a US Medicaid claims database. Pharmacoepidemiol Drug Saf. 2003; 12:103-111. [PubMed: 12647699]

29. Centers for Medicare \& Medicaid Services. [December 22, 2013] Medicaid Statistical Information System (MSIS) Tables. http://www.cms.gov/MedicaidDataSourcesGenInfo/MSIS/list.asp.

30. Centers for Medicare \& Medicaid Services. [December 22, 2013] Medicaid Analytic eXtract (MAX) Validation Reports. http://www.cms.gov/MedicaidDataSourcesGenInfo/MVR/list.asp. 
31. Medicare Payment Advisory Commission. Report to the Congress: New Approaches in Medicare. 2004

32. Byrne DD, Newcomb CW, Carbonari DM, Nezamzadeh MS, Leidl KB, Herlim M, et al. Prevalence of diagnosed chronic hepatitis B infection among U.S. Medicaid enrollees, 2000-2007. Ann Epidemiol. 2014; 24:418-423. [PubMed: 24703196]

33. Keyes M, Andrews R, Mason ML. A methodology for building an AIDS research file using Medicaid claims and administrative data bases. J Acquir Immune Defic Syndr. 1991; 4:10151024. [PubMed: 1832459]

34. Gunthard HF, Aberg JA, Eron JJ, Hoy JF, Telenti A, Benson CA, et al. Antiretroviral treatment of adult HIV infection: 2014 recommendations of the International Antiviral Society-USA Panel. JAMA. 2014; 312:410-425. [PubMed: 25038359]

35. Yeni PG, Hammer SM, Carpenter CC, Cooper DA, Fischl MA, Gatell JM, et al. Antiretroviral treatment for adult HIV infection in 2002: updated recommendations of the International AIDS Society-USA Panel. JAMA. 2002; 288:222-235. [PubMed: 12095387]

36. Lo Re V 3rd, Volk J, Newcomb CW, Yang YX, Freeman CP, Hennessy S, et al. Risk of hip fracture associated with hepatitis $\mathrm{C}$ virus infection and hepatitis $\mathrm{C} /$ human immunodeficiency virus coinfection. Hepatology. 2012; 56:1688-1698. [PubMed: 22619086]

37. Baron JA, Barrett J, Malenka D, Fisher E, Kniffin W, Bubolz T, et al. Racial differences in fracture risk. Epidemiology. 1994; 5:42-47. [PubMed: 8117781]

38. Fang J, Freeman R, Jeganathan R, Alderman MH. Variations in hip fracture hospitalization rates among different race/ethnicity groups in New York City. Ethn Dis. 2004; 14:280-284. [PubMed: 15132215]

39. Brauer CA, Coca-Perraillon M, Cutler DM, Rosen AB. Incidence and mortality of hip fractures in the United States. JAMA. 2009; 302:1573-1579. [PubMed: 19826027]

40. Wright NC, Saag KG, Curtis JR, Smith WK, Kilgore ML, Morrisey MA, et al. Recent trends in hip fracture rates by race/ethnicity among older US adults. J Bone Miner Res. 2012; 27:2325-2332. [PubMed: 22692958]

41. Kish, L. Survey Sampling. John Wiley \& Sons, Inc.; New York, NY: 1965.

42. Ray WA, Griffin MR, Fought RL, Adams ML. Identification of fractures from computerized Medicare files. J Clin Epidemiol. 1992; 45:703-714. [PubMed: 1619449]

43. Braitman LE, Rosenbaum PR. Rare outcomes, common treatments: analytic strategies using propensity scores. Ann Intern Med. 2002; 137:693-695. [PubMed: 12379071]

44. D'Agostino RB Jr. Propensity score methods for bias reduction in the comparison of a treatment to a non-randomized control group. Stat Med. 1998; 17:2265-2281. [PubMed: 9802183]

45. Stuart EA. Matching methods for causal inference: A review and a look forward. Stat Sci. 2010; 25:1-21. [PubMed: 20871802]

46. Fine J, Gray RJ. A proportional hazards model for the subdistribution of competing risk. J Am Stat Assoc. 1999; 94:496-509.

47. Collett, D. Modeling survival data in medical research. Chapman and Hall; New York: 2003.

48. Bedimo R, Maalouf NM, Zhang S, Drechsler H, Tebas P. Osteoporotic fracture risk associated with cumulative exposure to tenofovir and other antiretroviral agents. AIDS. 2012; 26:825-831. [PubMed: 22301411]

49. Fakruddin JM, Laurence J. HIV envelope gp120-mediated regulation of osteoclastogenesis via receptor activator of nuclear factor kappa B ligand (RANKL) secretion and its modulation by certain HIV protease inhibitors through interferon-gamma/RANKL cross-talk. J Biol Chem. 2003; 278:48251-48258. [PubMed: 12975380]

50. Gibellini D, De Crignis E, Ponti C, Cimatti L, Borderi M, Tschon M, et al. HIV-1 triggers apoptosis in primary osteoblasts and HOBIT cells through TNF-alpha activation. J Med Virol. 2008; 80:1507-1514. [PubMed: 18649336]

51. Gilbert L, He X, Farmer P, Rubin J, Drissi H, van Wijnen AJ, et al. Expression of the osteoblast differentiation factor RUNX2 (Cbfa1/AML3/Pebp2alpha A) is inhibited by tumor necrosis factoralpha. J Biol Chem. 2002; 277:2695-2701. [PubMed: 11723115] 
52. Pignata S, Daniele B, Galati MG, Esposito G, Vallone P, Fiore F, et al. Oestradiol and testosterone blood levels in patients with viral cirrhosis and hepatocellular carcinoma. Eur J Gastroenterol Hepatol. 1997; 9:283-286. [PubMed: 9096431]

53. Soriano V, Puoti M, Peters M, Benhamou Y, Sulkowski M, Zoulim F, et al. Care of HIV patients with chronic hepatitis B: updated recommendations from the HIV-Hepatitis B Virus International Panel. AIDS. 2008; 22:1399-1410. [PubMed: 18614862]

54. Bhattacharya D, Thio CL. Review of hepatitis B therapeutics. Clin Infect Dis. 2010; 51:12011208. [PubMed: 20954965]

55. Fleishman JA, Gebo KA, Reilly ED, Conviser R, Christopher Mathews W, Todd Korthuis P, et al. Hospital and outpatient health services utilization among HIV-infected adults in care 2000-2002. Med Care. 2005; 43:III40-52. [PubMed: 16116308]

56. Althoff KN, Buchacz K, Hall HI, Zhang J, Hanna DB, Rebeiro P, et al. U.S. trends in antiretroviral therapy use, HIV RNA plasma viral loads, and CD4 T-lymphocyte cell counts among HIVinfected persons, 2000 to 2008. Ann Intern Med 2012. 157:325-335.

57. Ioannou GN. Hepatitis B virus in the United States: infection, exposure, and immunity rates in a nationally representative survey. Ann Intern Med. 2011; 154:319-328. [PubMed: 21357909] 


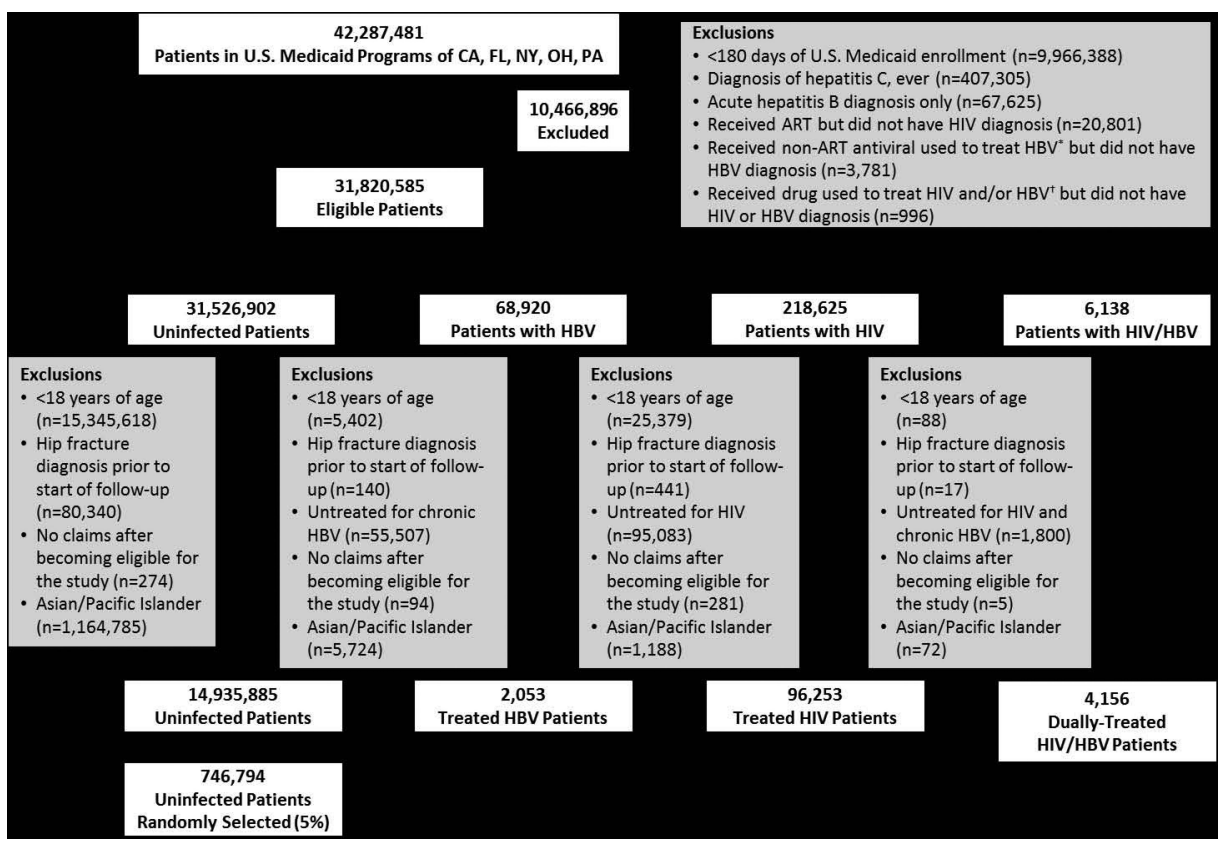

Figure 1.

Selection of patients in the study.

Abbreviations: $A R T=$ antiretroviral therapy; HIV=human immunodeficiency virus;

$\mathrm{HBV}=$ hepatitis $\mathrm{B}$ virus

* Non-ART antivirals used to treat chronic HBV were defined by a prescription claim for: adefovir, entecavir, telbivudine, or interferon alfa.

$\dagger$ Drugs used to treat HIV and/or HBV were defined by a prescription claim for: lamivudine, tenofovir, or emtricitabine. 

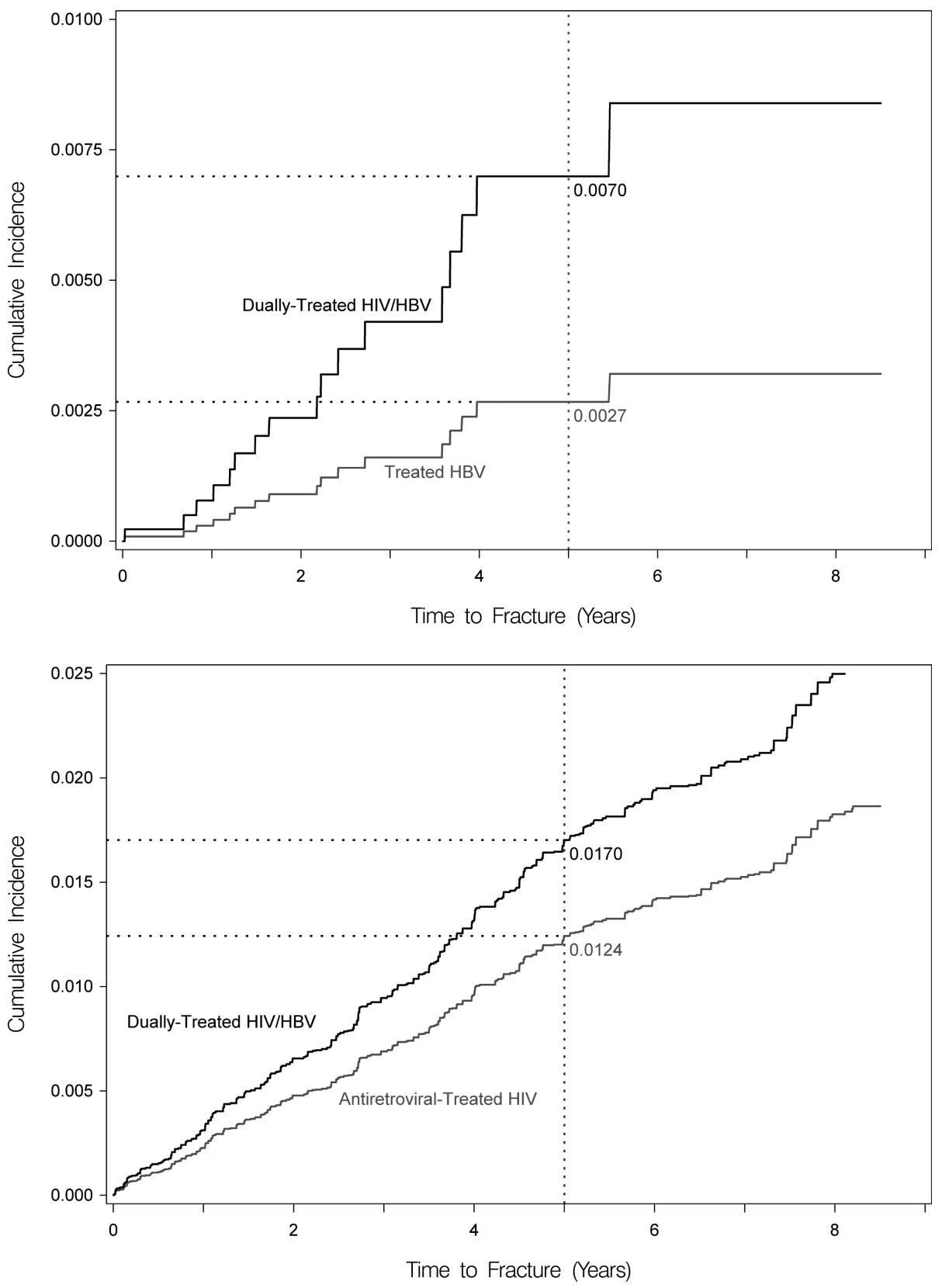

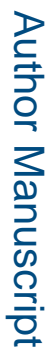

$J$ Viral Hepat. Author manuscript; available in PMC 2016 November 01. 


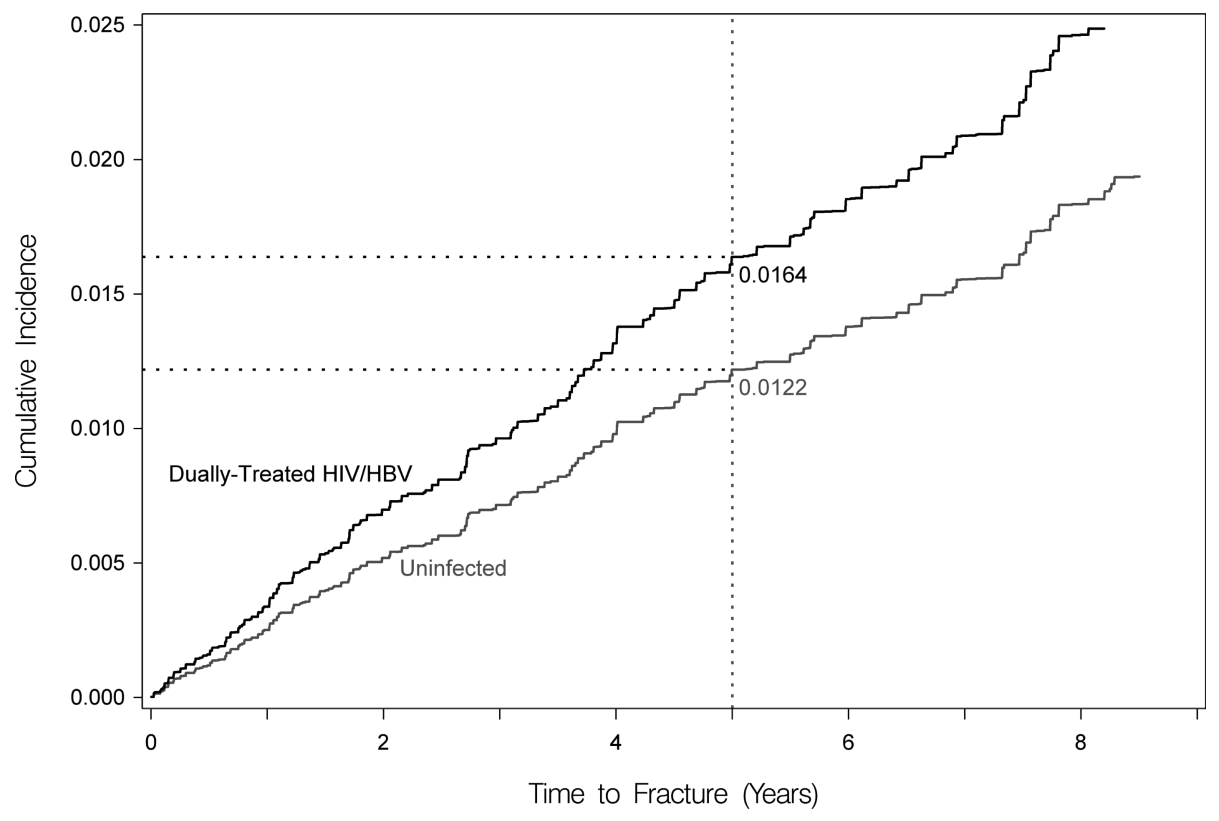

Figure 2. Standardized cumulative incidences (i.e., risks) of hip fracture, based on competing risk regression analyses

Estimates of the cumulative incidence of hip fracture are reported for each group. Estimates are standardized to the characteristics of dually-treated HIV/hepatitis B virus coinfected patients.

(A) Standardized cumulative incidences (i.e., risks) of hip fracture between dually-treated HIV/hepatitis B virus-coinfected (denoted by black line) and treated hepatitis B virusmonoinfected patients (denoted by gray line). Coinfected patients in this figure represent only a subset of all coinfected patients. Remaining coinfected patients could not be matched to the hepatitis B virus-monoinfected patients because the characteristics of the two groups differed so markedly. Standardized for age and sex after matching.

(B) Standardized cumulative incidences (i.e., risks) of hip fracture between dually-treated $\mathrm{HIV} /$ hepatitis B virus-coinfected (denoted by black line) and antiretroviral-treated HIVmonoinfected patients (denoted by gray line). Standardized using age, sex, and tenofovir use after matching.

(C) Standardized cumulative incidences (i.e., risks) of hip fracture between dually-treated HIV/hepatitis B virus-coinfected (denoted by black line) and HIV/hepatitis B virusuninfected patients (denoted by gray line). Standardized for age and sex after matching. 


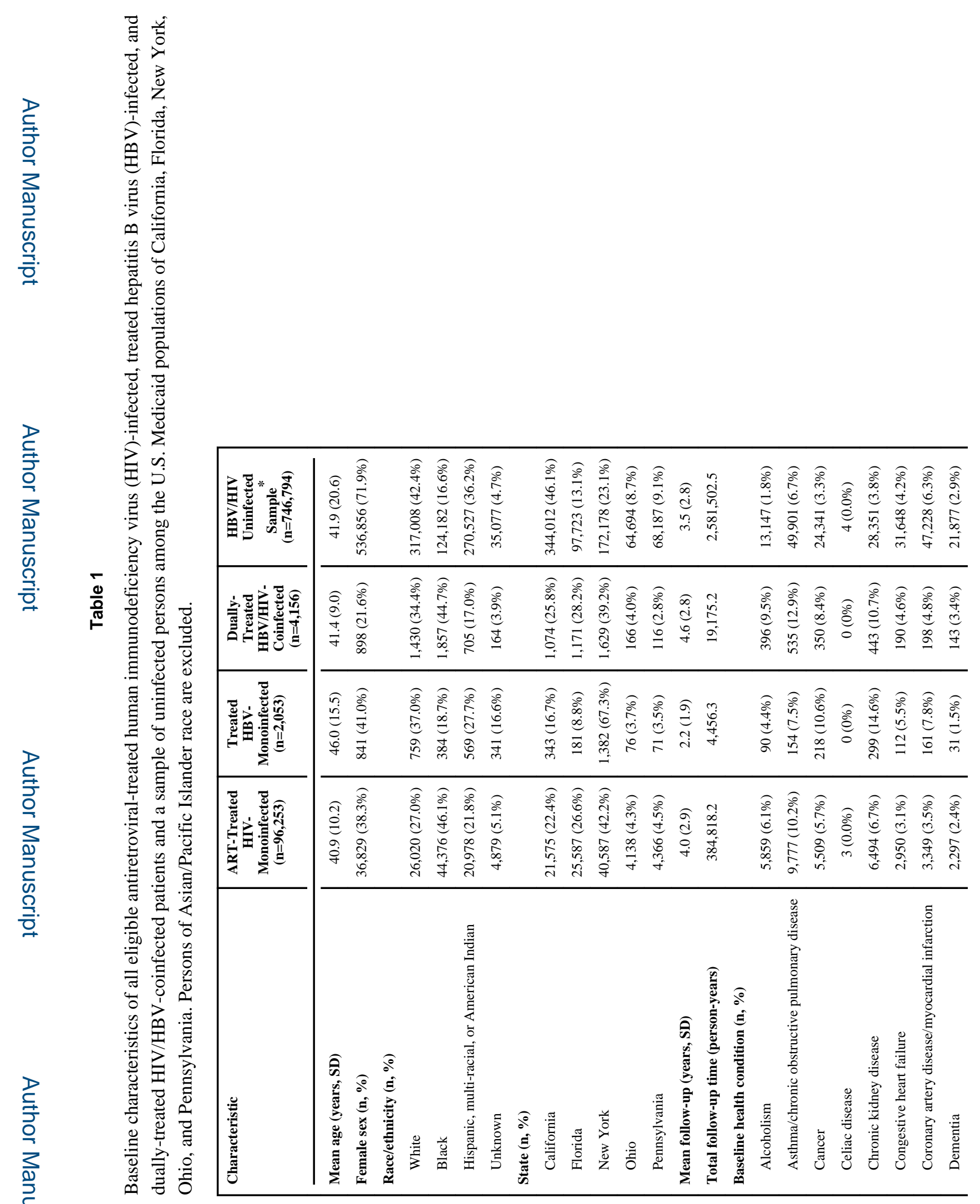

J Viral Hepat. Author manuscript; available in PMC 2016 November 01. 


\section{Table 2}

Unadjusted incidence rates and standardized cumulative incidences of hip fracture for dually-treated HIV/ hepatitis B virus (HBV)-coinfected patients compared to treated HBV-monoinfected, antiretroviral therapytreated HIV-monoinfected, and HIV/HBV-uninfected persons. Results exclude persons of Asian/Pacific Islander race.

\begin{tabular}{|c|c|c|c|c|c|c|c|c|}
\hline \multirow[b]{2}{*}{ Cohort Comparison } & \multicolumn{3}{|c|}{ Population } & \multicolumn{5}{|c|}{ Matched Sample } \\
\hline & No. Patients & No. Hip Fractures & $\begin{array}{c}\text { Raw Hip } \\
\text { Fracture } \\
\text { Incidence } \\
\text { Rate, } \\
\text { Events/ } \\
1,000 \\
\text { person- } \\
\text { years (95\% } \\
\text { CI) }\end{array}$ & No. Patients & No. Hip Fractures & No. Deaths & $\begin{array}{c}\text { Risk Of } \\
\text { Hip } \\
\text { Fracture } \\
\text { at } 5 \\
\text { Years } \\
(\%)^{*}\end{array}$ & $\begin{array}{c}\text { Additional } \\
\text { Hip } \\
\text { Fractures } \\
\text { Per 1,000 } \\
\text { Dually- } \\
\text { Treated } \\
\text { HIV/HBV } \\
\text { Patients at } \\
5 \text { Years }\end{array}$ \\
\hline Treated HBV & 2,053 & 11 & $2.5(1.2-4.4)$ & 1,007 & 9 & 95 & 0.27 & \\
\hline Dually-Treated HIV/HBV & 4,156 & 67 & $3.5(2.7-4.4)$ & 4,155 & 67 & 649 & 1.70 & 4.6 \\
\hline Antiretroviral-Treated HIV & 96,253 & 808 & $2.1(2.0-2.3)$ & 16,579 & 172 & 2,239 & 1.24 & \\
\hline Dually-Treated HIV/HBV & 4,156 & 67 & $3.5(2.7-4.4)$ & 4,150 & 67 & 646 & 1.64 & 4.2 \\
\hline
\end{tabular}

Abbreviations: CI, confidence interval; HBV, hepatitis B virus; HIV, human immunodeficiency virus

* Absolute risk of hip fracture was determined based on standardized cumulative incidences. Standardization to the characteristics of the coinfected patients was accomplished by weighting. Cumulative incidences were adjusted for competing risks. Differences in the cumulative incidences of coinfected patients arise from differences in the sample sizes as well as from having tenofovir as one of the standardizing characteristics for one of the models and not the others. See figures for additional details.

${ }^{\dagger}$ Because only a subset $(\mathrm{n}=1,007)$ of dually-treated HIV/HBV-coinfected patients were able to matched to treated HBV-monoinfected patients, the cumulative incidence of hip fracture for the coinfected cohort in this comparison differed from that of the other comparisons. 